\title{
Amplitude and frequency spectrum of temporomandibular joint sounds from subjects with and without other signs/symptoms of temporomandibular disorders
}

\author{
T. SANO*, S.-E. WIDMALM ${ }^{\dagger}$, P.-L. WESTESSON, K. TAKAHASHI, H. YOSHIDA", \\ K. MICHI ${ }^{\S} \& \mathrm{~T}$. OKANO* *Department of Oral Radiology, Showa University School of Dentistry, Tokyo, Japan; ${ }^{\dagger}$ Department \\ of Biologic $\theta$ Materials Sciences, University of Michigan School of Dentistry, Ann Arbor, MI, U.S.A.; ${ }^{\ddagger}$ Department of Radiology, University of \\ Rochester, Rochester, NY, U.S.A.; ${ }^{\S}$ First Department of Oral and Maxillofacial Surgery, Showa University School of Dentistry, Tokyo, Japan; \\ "Department of Stomatology, Institute of Clinical Medicine, University of Tsukuba, Ibaraki, Japan
}

SUMMARY Temporomandibular joint (TMJ) sound is one of the most commonly recognized signs in patients with temporomandibular disorders (TMD) but is also frequently seen in asymptomatic individuals. Sound recording is therefore only meaningful if the sounds from a normal healthy joint can be differentiated from those in patients. In this study, the amplitude and power spectrum of the TMJ sounds from symptomatic patients and asymptomatic individuals were recorded and com- pared. The result showed that TMJ sounds from symptomatic patients had a larger amplitude than sounds from asymptomatic subjects. A significant proportion of sounds had frequencies between 2000 and $3000 \mathrm{~Hz}$. It was concluded that the characteristic amplitude is worthy of further study as a sign of possible diagnostic value. Secondly, the bandwidth of the sensors used at electronic TMJ sound recording should not be less than $3000 \mathrm{~Hz}$.

\section{Introduction}

Temporomandibular joint (TMJ) sound, has been considered an important physical sign of joint dysfunction and/or joint pathology (Ekensten, 1952; Watt, 1963; Farrar, 1978; Isberg-Holm \& Westesson, 1982; Eriksson \& Westesson, 1983). Sound in this context refers to the audible vibrations with a frequency in the range of 20 to $20000 \mathrm{~Hz}$. Joint sound is one of the most commonly recognized signs of temporomandibular disorders (TMD) but is frequently also present in otherwise asymptomatic individuals (Widmer, 1989; Stockstill \& Mohl, 1991; Tallents et al., 1993). It can therefore not be used with high specificity in the diagnoses of TMD unless a differentiation between the sounds from asymptomatic compared to symptomatic patients can be carried out by objective methods of recording and classification of the sound.
A significant number of studies have tried to differentiate the sounds based upon characteristics such as amplitude and frequency (Findlay \& Kilpatrick, 1960; Ouellette, 1974; Drum \& Litt, 1987; Oster et al., 1984; Gay \& Bertolami, 1987; Heffez \& Blaustein, 1986; Hutta et al., 1987; Gay et al., 1987; Gay \& Bertolami, 1988). A general agreement has, however, not been reached and some authors claim that the joint sounds do not have a significant energy content in the frequency range above approximately $1000 \mathrm{~Hz}$ (Wabeke et al., 1992; Ishigaki, Bessette \& Maruyama, 1993) whereas others have found substantial amounts of energy in the frequency range well above $1000 \mathrm{~Hz}$ (Widmalm et al., 1992; Yoshida et al., 1994; Widmalm et al., 1996; Widmalm, Williams \& Adams, 1996). It therefore seems important to use a recording device that allows recording of frequencies both below and above $1000 \mathrm{~Hz}$. 
Table 1. Criteria for separating patients with TMJ sounds into experimental (symptomatic) and control (asymptomatic) groups

\begin{tabular}{|c|c|}
\hline Inclusion criteria for subjects in the control group & Inclusion criteria for subjects in the experimental group \\
\hline 1. No pain in the head or neck area. & 1. Pain in any of the TMJ-or masticatory muscle areas. \\
\hline $\begin{array}{l}\text { 2. No pain at palpation of any of the masseter, temporalis, pterygoid, } \\
\text { digastric, sterno-cleidomastoid, posterior cervical or epicranius muscles. }\end{array}$ & 2. Pain at digital palpation of any of the jaw muscles. \\
\hline 3. No pain at jaw movement or chewing. & 3. Inter-incisal opening $\leq 38 \mathrm{~mm}$ (edge to edge). \\
\hline 4. Inter-incisal opening $>38 \mathrm{~mm}$ (edge to edge). & 4. Right or left lateral or protrusive movement $\leq 7 \mathrm{~mm}$. \\
\hline \multicolumn{2}{|l|}{ 5. Right/left lateral and protrusive movement $>7 \mathrm{~mm}$. } \\
\hline 6. No significant deviation $(>2 \mathrm{~mm}$ ) from a straight opening-closing & \\
\hline
\end{tabular}

The aims of this study were to compare the amplitude and energy distribution of TMJ sounds from subjects without and with signs of TMD. Further, it was the aim to analyse the energy content of TMJ sounds in the lower and higher parts of the frequency range of 100 to $3000 \mathrm{~Hz}$. The first null hypothesis was that there were no difference in amplitude of TMJ sounds from subjects with and without signs of TMD. The second null hypothesis was that there was no difference in the energy distribution as seen in the power spectra of TMJ sounds from subjects with and without signs of TMD. And the final null hypothesis was that the energy content of the TMJ sounds was insignificant in the frequency area above $1000 \mathrm{~Hz}$.

\section{Materials and methods}

\section{Selection of subjects}

Informed consent was obtained from the subjects who were randomly selected from a population of patients referred because of suspected TMD to the First Department of Oral and Maxillofacial Surgery of Showa University, Tokyo. The patients were checked for TMJ sounds using a stethoscope. The patients were examined this way by three members of the research team and patients who had sounds recognized by all three members of the team were included in this study. A total of 49 patients were included. There were 23 males and 26 females ranging in age from 20 to 63 years. The subjects were divided into two groups; one experimental group and one control group. The patients in the control group were those who demonstrated only TMJ sound and no other signs or symptoms of TMD. The patients in the experimental group were those who had evidence of TMJ sounds and at least one other sign or symptom of TMD, as listed in Table 1.

\section{Electronic sound recording system}

The TMJ sounds were recorded with a clinical probe microphone system with electric condenser microphones* (Yoshida et al., 1994). All recordings were performed in a sound-proof room at Showa University Dental Hospital. The probes were secured by ear rods made of acrylic resin and inserted into the auditory meati bilaterally. Carefully checks were made to ensure that the ends of the probes were at least $15 \mathrm{~mm}$ from the entrance of the canals but not more than $20 \mathrm{~mm}$ to avoid the risk of causing discomfort. The microphones have an almost flat frequency response up to $10 \mathrm{kHz}$. The TMJ sound signals were recorded with a digital tape recorder ${ }^{\dagger}$ using a sampling rate of $48 \mathrm{kHz}$, high pass filtered with a cut-off frequency of $22.4 \mathrm{~Hz}$ and low pass filtered with a cut-off frequency of $3.9 \mathrm{kHz}$. Attenuation characteristics were $46 \mathrm{~dB} /$ octave. $^{\ddagger}$ The recordings were downsampled to $10 \mathrm{kHz}$ before analysis.

\section{Sound recording procedure}

The TMJ sounds were recorded during five mouth opening and closing cycles made at a rate of 40 cycles per minute. The jaw movements were standardized by having the subjects following the silent signals of a metronome (red light signals turned on and off). The recordings were performed in a sound-proof room with ambient noise amplitude less than $25 \mathrm{~dB}$.

\footnotetext{
* Knowles EA, 1842; Knowles Electronics Co., Burgess Hill, Sussex, U.K.

+ Sony DTC-300ES; Sony Corporation, Tokyo, Japan.

${ }^{\ddagger}$ Rion SA-33D; Rion Co., Tokyo, Japan.
} 
Table 2. Amplitude of TMJ sounds during opening-closing cycles

\begin{tabular}{lll}
\hline & $\begin{array}{l}\text { Experimental group } \\
\text { Average } \pm \text { SD in dB } \\
\text { (min.-max.) }\end{array}$ & $\begin{array}{l}\text { Control group } \\
\text { Average } \pm \text { SD in dB } \\
\text { (min.-max.) }\end{array}$ \\
\hline Opening & $\begin{array}{l}25 \cdot 4 \pm 12 \cdot 8 \\
(7 \cdot 6-61 \cdot 8)\end{array}$ & $\begin{array}{l}16 \cdot 5 \pm 8 \cdot 5 \\
(0-32 \cdot 0)\end{array}$ \\
Closing & $24 \cdot 8 \pm 10 \cdot 4$ & $13 \cdot 9 \pm 7 \cdot 1$ \\
& $(6 \cdot 4-42 \cdot 1)$ & $(1 \cdot 4-26 \cdot 7)$ \\
\hline
\end{tabular}

Average values of sounds from five consecutive opening-closing cycles are given. The average amplitude (above noise level) was higher in the experimental group (subjects with at least one sign/symptom of TMD) than in the control group during opening $(P<0.05)$ and during closing $(P<0.01)$.

Five recordings were made from each subject during mandibular rest to measure the amount of artifacts, such as room noise, respiration and other ambient noises. Each sound and noise sample to be used in the final analysis had a length of 8192 data points $(819 \mathrm{~ms})$. For each subject, only the recordings from the side with the highest TMJ sound amplitude, were used in the analysis.

Classification of TMJ sounds by analysis in the time domain

The TMJ sounds were noted if the signal to noise ratio was at least $6 \mathrm{~dB}$. The maximal amplitude levels were measured in each opening and in each closing cycle and averaged over five opening closing cycles (Table 2). The sounds were classified according to whether they occurred during opening or during closing and to where they occurred in relation to the maximal jaw opening degree (Table 3). They were designated as occurring in the early phase (E) if they occurred during the first third, intermediate (I) if they occurred during the middle third and late (L) if they occurred during the last third of the opening or closing movement.

\section{Classification of TMJ sounds by spectral analysis}

The TMJ sound's power spectrum, which plots the energy in $\mathrm{dB}$ against frequency in $\mathrm{Hz}$, was calculated by means of Fast Fourier Transform. The spectra of five opening-closing sounds and five noise samples were averaged and measured by one octave band analysis. The spectral analysis was performed on the frequencies from $100 \mathrm{~Hz}$ up to $3000 \mathrm{~Hz}$. Analysis of the energy content was performed by dividing the frequency spectrum into five successive octave bands with the centre frequencies 125, 250, 500, 1000 and $2000 \mathrm{~Hz}$. It was estimated in which of the five successive octave bands the various opening and closing TMJ sounds had their maximal energy content (Yoshida et al., 1994). The sounds were in this way classified into five types, type I-type V, depending on the octave band in which the maximal energy content was located. It was classified as type I if the maximal energy was in the first octave band, type II if the maximal energy was in the second octave band, etc.

The influence of background noise was compensated for by subtraction of the noise spectrum from the sound spectrum and the power level for each of the five octave bands were computed for each averaged sound sample (Yoshida et al., 1994).
Table 3. Classification of TMJ sounds according to location in relation to degree of jaw opening

\begin{tabular}{|c|c|c|c|c|c|c|}
\hline & \multicolumn{3}{|c|}{ Experimental group } & \multicolumn{3}{|c|}{ Control group } \\
\hline & Early & Intermediate & Late & Early & Intermediate & Late \\
\hline $\begin{array}{c}\text { Opening } \\
(\%)\end{array}$ & $4 \cdot 8$ & $28 \cdot 6$ & $66 \cdot 7$ & $0 \cdot 0$ & $39 \cdot 3$ & $60 \cdot 7$ \\
\hline Closing (\%) & $15 \cdot 0$ & $65 \cdot 0$ & $20 \cdot 0$ & $18 \cdot 5$ & $77 \cdot 8$ & $3 \cdot 7$ \\
\hline
\end{tabular}

The table shows how many of the TMJ sounds occurred in the early, intermediate and late phases of the opening and closing jaw movements. No differences were seen between groups. Most sounds occurred during the late phase of the opening and the intermediate phase of the closing movement. 


\section{Statistical methods}

The Mann-Whitney rank sum test was used for testing for differences between groups and between opening and closing sounds within subjects.

\section{Results}

The TMJ sounds from subjects, who had at least one additional sign/symptom of TMD (experimental group), had significantly larger amplitude during opening $(P<0.05)$ and closing $(P<0.01)$ than sounds from otherwise asymptomatic subjects (control group) (Table 2). The mean amplitude (above the noise level) was $25 \mathrm{~dB}$ in the experimental group and $15 \mathrm{~dB}$ in the control group. No differences were found between the amplitude of opening and closing sounds within the groups.

The distribution of TMJ sounds in relation to jaw opening degree was about the same in both groups (Table 3). About $64 \%$ of the opening sounds occurred in the late phase and about $71 \%$ of the closing sounds occurred during the intermediate phase.

The spectral analysis did not reveal any differences between groups (Table 4). Thirty-eight per cent of the sounds had their energy peaks in the 1000$2000 \mathrm{~Hz}$ octave bands.

\section{Discussion}

The results of this study showed that TMJ sounds from patients who also had other signs of TMD, had larger amplitude than sounds from otherwise asymptomatic subjects and that the frequency content extended well beyond $1000 \mathrm{~Hz}$ in both groups. This supports the concept that TMJ sound is an important sign to consider in TMD diagnosis. It also supports recent claims that high sampling rates and microphones with wide bandwidth have to be used in TMJ sound recording (Yoshida et al., 1994; Widmalm et al., 1996; Widmalm, Williams \& Adams, 1996). Thirty-eight per cent of the sounds had their energy peaks in the 1000-2000 Hz octave bands. This is contrary to reports that claim that TMJ sounds have their energy peaks below $1000 \mathrm{~Hz}$ and only insignificant energy above that limit (Christensen $\&$ Donegan, 1992; Ishigaki et al., 1993). Knowledge about the true bandwidth of TMJ sounds is important when selecting the appropriate sensors.
Table 4. Distribution of sound types as classified according to frequency distribution

\begin{tabular}{|c|c|c|c|c|c|}
\hline $\begin{array}{l}\text { Type of sound } \\
\text { Centre frequency }\end{array}$ & $\begin{array}{l}\mathrm{I} \\
125\end{array}$ & $\begin{array}{l}\text { II } \\
250\end{array}$ & $\begin{array}{l}\text { III } \\
500\end{array}$ & $\begin{array}{l}\text { IV } \\
1000\end{array}$ & $\begin{array}{l}V \\
2000\end{array}$ \\
\hline \multicolumn{6}{|l|}{ Experimental group } \\
\hline Opening phase $(\%)$ & $19 \cdot 0$ & $9 \cdot 5$ & $38 \cdot 1$ & $33 \cdot 3$ & $0 \cdot 0$ \\
\hline Closing phase $(\%)$ & $5 \cdot 3$ & $5 \cdot 3$ & $52 \cdot 6$ & $26 \cdot 3$ & $10 \cdot 5$ \\
\hline \multicolumn{6}{|l|}{ Control group } \\
\hline Opening phase $(\%)$ & $15 \cdot 4$ & $0 \cdot 0$ & $30 \cdot 8$ & $50 \cdot 0$ & $3 \cdot 8$ \\
\hline Closing phase $(\%)$ & $12 \cdot 5$ & $8 \cdot 3$ & $41 \cdot 7$ & $37 \cdot 5$ & $0 \cdot 0$ \\
\hline
\end{tabular}

The table shows how the various types of TMJ sounds were distributed. It can for instance be seen that $19.0 \%$ of the subjects in the experimental group had TMJ sounds during opening with the maximal energy in the first octave band (centre frequency $125 \mathrm{~Hz}), 9 \cdot 5 \%$ had their maximal energy in the second octave band during opening, etc. No differences in distribution were observed between groups. It is noteworthy though that $38 \%$ of the sounds had their energy peaks in the fourth to fifth octave bands which is well above the frequency range used in many recent studies. Some figures do not add up to $100 \%$ due to 'round-off error'.

The spectral analysis did not reveal any differences between groups. The number of subjects may have to be larger, the method for spectral analysis may have to be more sophisticated and/or the bandwidth of the microphones may have to be increased to reveal possible differences. Those aspects will be considered in future studies by testing microphones with bandwidth up to $20 \mathrm{kHz}$ and using newly published methods for displaying the time-frequency distributions of the sounds (Brown, Williams \& Widmalm, 1994; Williams, 1996).

The influence of background noise was compensated for by subtraction of the noise spectrum from the sound spectrum (Yoshida et al., 1994). This is especially important for the low end of the frequency range where the noise energy is relatively high.

A large part of the TMJ sound recordings discussed in the literature have been made using accelerometers placed in contact with the skin over the TMJ (Christensen \& Donegan, 1992; Ishigaki et al., 1993). Accelerometers are widely used for vibration analysis in engineering applications. One important prerequisite for accurate analysis is, however, that the accelerometer is rigidly fastened to the body undergoing acceleration (Morris, 1993). Such an attachment can, however, not be made with patients. A non-rigid attachment means that the frequency properties of the recorded signal cannot be accurately 
recorded with loss especially of the high frequencies. We therefore consider a microphone, which does not make contact with the skin, to be a better choice for sound recording.

When discussing the loudness of the TMJ sounds it should be noted that the electronically recorded amplitude may not be the best measurement unless combined with information about the frequency content. Sounds with a frequency content in the range 1000$3000 \mathrm{~Hz}$ are perceived as very much louder than sounds in the range $20-200 \mathrm{~Hz}$ if the electronically recorded amplitude is the same. New methods revealing the time-frequency distribution of the sound (Widmalm, Williams \& Zheng, 1991; Williams, 1996) have to be, and will be used in our future studies, for true comparisons of loudness.

It is concluded that the sound characteristic amplitude is worthy of further study as a sign of possible diagnostic value, provided electronic recording is used, and that the bandwidth of the sensors used at electronic TMJ sound recording has to be not less than about $3000 \mathrm{~Hz}$. The area of signal processing is rapidly progressing and new powerful methods are being developed (Williams, 1996). Before these are applied to large subject groups the optimal bandwidth of sensors to be used should be established.

\section{Acknowledgments}

We would like to thank Drs Tanetoshi Miura and Hareo Hamada, Tokyo Denki University, Tokyo, Japan, for their technical advice and Dr Kaoru Okabe for his technical assistance. This work was supported by Grants-in-Aid for Scientific Research from the Ministry of Education, Science and Culture of Japan (Nos 08771659 and 10771037).

\section{References}

Brown, M.L., Williams, W.J. \& Widmalm, S.E. (1994) Automatic classification of temporomandibular joint sounds. In: ASME Press Series on International Advances in Design Productivity. Intelligent Engineering Systems Through Artificial Neural Networks (eds C.H. Dagli, B.R. Fernández, J. Ghosh \& R.T.S. Kumara), vol. 4, 725. Asme Press, New York.

Christensen, L.V. \& Donegan, S.J. (1992) Temporomandibular joint vibration analysis in a sample of non-patients. Journal of Craniomandibular Practice, 10, 35.

Drum, R. \& LITT, M. (1987) Spectral analysis of temporomandibular joint sounds. Journal of Prosthetic Dentistry, 58, 485.
Ekensten, B. (1952) Phonograms of anomalies of the temporomandibular joint in motion. Odontologisk Tidskrift, 60, 235.

ERIKSSON, L. \& WESTESSON, P.L. (1983) Clinical and radiological study of patients with anterior disk displacement of the temporomandibular joint. Swedish Dental Journal, 7, 55.

FARRAR, W.B. (1978) Characteristics of the condylar path in internal derangements of the TMJ. Journal of Prosthetic Dentistry, 39, 319.

Findlay, I.A. \& Kilpatrick, S.J. (1960) An analysis of the sounds produced by the mandibular joint. Journal of Dental Research, 39, 1163.

Gay, T. \& Bertolami, C.N. (1987) The spectral properties of temporomandibular joint sounds. Journal of Dental Research, 66, 1189.

GAy, T. \& Bertolami, C.N. (1988) The acoustical characteristics of the normal temporomandibular joint. Journal of Dental Research, 67, 56.

Gay, T., Bertolami, C.N., Donoff, R.B., Keith, D.A. \& Kelly, J.P. (1987) The acoustical characteristics of the normal and abnormal temporomandibular joint. Journal of Oral and Maxillofacial Surgery, 45, 397.

Heffez, L. \& Blaustein, D. (1986) Advances in sonography of the temporomandibular joint. Oral Surgery, Oral Medicine, Oral Pathology, 62, 486.

Hutta, J.L., Morris, T.W., Katzberg, R.W., Tallents, R.H. $\delta$ EsPELAND, M.A. (1987) Separation of internal derangements of the temporomandibular joint using sound analysis. Oral Surgery, Oral Medicine, Oral Pathology, 63, 151.

IsBerg-Holm, A.M. \& Westesson, P.L. (1982) Movement of disk and condyle in temporomandibular joints with clicking: an arthrographic and cineradiographic study on autopsy specimens. Acta Odontologica Scandinavica, 40, 151.

Ishigaki, S., Bessette, R.W. \& Maruyama, T. (1993) Vibration analysis of the temporomandibular joints with meniscal displacement with and without reduction. Journal of Craniomandibular Practice, 11, 192.

Morris, A.S. (1993) Principles of Measurement and Instrumentation, 363. Prentice Hall, New York.

Oster, C., Katzberg, R.W., Tallents, R.H., Morris, T.W., Bartholomew, J., Miller, T.L. \& Hayakawa, K. (1984) Characterization of temporomandibular joint sounds. Oral Surgery, Oral Medicine, Oral Pathology, 58, 10.

OuelLetTe, P.L. (1974) TMJ sound prints: electronic auscultation and sonographic audiospectral analysis of the temporomandibular joint. Journal of American Dental Association, 89, $623-628$.

Stockstill, J.W. \& Mohl, N.D. (1991) Evaluation of temporomandibular joint sounds. Diagnostic analysis and clinical implications. Dental Clinics of North America, 35, 75.

Tallents, R.H., Hatala, M., Katzberg, R.W. 8 Westesson, P.L. (1993) Temporomandibular joint sounds in asymptomatic volunteers. Journal of Prosthetic Dentistry, 69, 298.

Wabeke, K.B., Spruijt, R.J., van der Weyden, K.J. \& NaeiJe, M. (1992) Evaluation of a technique for recording temporomandibular joint sounds. Journal of Prosthetic Dentistry, 68, 676.

WATT, D.M. (1963) A preliminary report on the auscultation of the masticatory mechanism. Dental Practitioner, 14, 27. 
Widmalm, S.E., Westesson, P.L., Brooks, S.L., Hatala, M.P. \& PAESANI, D. (1992) Temporomandibular joint sounds: correlation to joint structure in fresh autopsy specimens. American Journal of Orthodontics and Dentofacial Orthopedics, 101, 60.

Widmalm, S.E., Williams, W.J. \& ADAms, B.S. (1996) The wave forms of temporomandibular joint sounds clicking and crepitation. Journal of Oral Rehabilitation, 23, 44.

Widmalm, S.E., Williams, W.J., Christiansen, R.L., Gunn, S.M. \& PARK, D.K. (1996) Classification of temporomandibular joint sounds based upon their reduced interference distribution. Journal of Oral Rehabilitation, 23, 35.

Widmalm, S.E., Williams, W.J. \& Zheng, C. (1991) Time frequency distributions of TMJ sounds. Journal of Oral Rehabilitation, 18, 403.
Widmer, C.G. (1989) Temporomandibular joint sounds: a critique of techniques for recording and analysis. Journal of Craniomandibular Disorders and Facial Oral Pain, 3, 213.

WiLliams, W.J. (1996) Reduced interference distributions: biological applications and interpretations. Proceedings of the IEEE, 84, 1 .

Yoshida, H., Sano, T., Kataoka, R., Takahashi, K. \& Michi, K. (1994) A preliminary investigation of a method of detecting temporomandibular joint sounds. Journal of Orofacial Pain, 8, 73.

Correspondence: Dr Sven E Widmalm, 1565 Kuehnle, Ann Arbor, MI 48103, U.S.A. E-mail: sew@umich.edu 